\title{
Cultural Connotation and Integration of Painting and Media in Contemporary Art
}

\author{
Bochen Zhang ${ }^{\text {a, * }}$ \\ Shandong University of Arts, Jinan, China. \\ *, a Bochenzhang@163.com
}

Keywords: Contemporary art; painting; video media; cultural connotation; integration.

\begin{abstract}
The world has already entered the age of image from the word age. Photography has a great influence on painting. Photographic painting is a new art style. As a new field of painting study, photographic painting has its significance in the cultural expression of modern art. Taking German artist Gerhard. Richter's work as an example, the randomness of its composition and the scalability of the image is analyzed. Based on the research of many famous artists at home and abroad, images are introduced. The aesthetic orientation is being accepted and adopted by more and more artists and the public. The emergence and development of photographic painting has an inherent connection with the development of art. Photographic painting is studied in the development of contemporary art, to find the exact theoretical basis of aesthetic theory.
\end{abstract}

\section{Introduction}

With the development of the image media, painting has been influenced and impacted by it. Painting is still the most mature way of art in the contemporary era. It occupies an irreplaceable position of the subject. The combination of painting and image has more possibilities for the cross and integration of various disciplines in the past [1]. Photographic painting is an important collectivistic genre in contemporary Chinese painting art. The image phenomenon and process of painting attract people's attention. The artist uses photographic painting to dissimilate and transform the traditional elements of the art of painting. The rebellion of the traditional painting art has been recognized by the broad audience. It is a special and reasonable phenomenon in the development of contemporary art.In the contemporary art of painting, only the photographic painting has been reorganized across the subject, which converts with the image resources. By using the visual effects of the image elements, the means of painting expression are extended. Since twentieth Century, artistic creation has been more inclusive. With the development of natural science, the concept of art and the method of creation were innovated. The characteristics of contemporary visual culture are becoming more and more inclined to image. Image data or observation and aesthetic orientation are being accepted and adopted by more and more artists [2]. In the history of the combination of painting and image in the west, a group of artists with international influence have mastered and praised this form of creation. It has been recognized by the international art scene. Photographic painting has the characteristics of precise objective reproducibility.

With the development of physics, the picture of the restored image is presented mechanically, which leads the popular culture to become an image-centered and perceptual form. The factors of image gradually occupy the dominant position of mass culture. The accuracy of the image features makes the photographic painting have a broad audience base. As a fully rendered object information, mechanical physics photography provides the most real detail [3]. As the presentation of the image features, the outstanding traditional works of painting have been fully expressed. Gerhard Richter, a leading figure in imagery and the German artist, thinks that the lens is not emotional, which only plays the role of recording. To a certain extent, it is objective. Richter's photographic painting makes painting closer to the picture. From the methodology of a retinal symbol painting, painting and visual objects are butted. It tries to reflect the essence of vision and create a direct face of the audience [4].The image noumenon is fully embodied in its painting. When choosing a reference picture, 
Richter's paintings often do not make a deliberate choice. This reflects Richter's inner sensitivity and inexorability. IN fact, the image content of Richter's works reflects his inner intuition at some time, which comes from the unconscious of the artist. The selection of images may be a false problem. The key is that Richter provides a way to reorganize the picture. Each part of the object is understood in the process of depicting. Compared with the original photograph, photography is capturing the shape of the object and bypassing the precise understanding and expression of the object, and finally presenting it to the audience with the vision [5].

\section{The Art of Painting}

Since the birth of photography, image has become the main medium of the age of visual culture. In the middle of the nineteenth Century, photography produced a great impact on painting. Many of the functions of the original painting art are threatened, which makes the painting art faced with many problems about the future and the significance. The imitation and reproduction of the true world of painting is shaken from the significance of existentialism. Many painters even look at the future of painting art from the state of the last day of the world [6]. They think photography has damaged the art of painting. From the development of the western art history, the emergence of photography once made the painting art deeply puzzled. Some artists try to explore the depth of the painting language and the changes in surface features. The art of painting has entered the trend of modern and post-modern development. Its main creative methods and procedures have enabled many artists to transform the resources of photography. The visual mechanical imaging of photography is used to guide and reorganize the traditional elements of painting. In such a concept, photography makes the visual culture of the traditional painting text in a new explanation of the context. Both connotation and extension forms have been expanded to derive new semantics. For example, the dancers Degas Impressionist series, which uses photography as painting materials portrayed, and maintained a strong personal style painting language. The proposition of luncheon on Mamet's Meadow comes from a photo of a friend's party at the weekend. Photography is a method used in the process of creation, and the standard is painting. Photos have picture balance. Long shots, medium shots and close shots are combined. Its identity and function are a blueprint of the painting. In a strict sense, it is a sketch borrowed from painting and melts into the concept and art of painting. The overall concept of creation has no big impact, or just an inspiration for the creation of paintings.

Leslie Clos, an ultra-realistic painter in the United States, used photography in his early experiments. By the high magnification of optical imaging, the surface details of the object are observed and displayed in the way of painting. In the large size of the frame, the public can feel the skin pores, the texture of clothes and hair slender texture [7]. The other name of hyperrealism seems to explain the relationship between photography and painting more clearly. Photorealism follows the photographic realism. Painters do not sketch directly. It often uses the camera to capture HD photographic images. The purpose is to extract the subjective feelings of the artist to obtain the feeling of the image. Optical mechanical lens is used to replace the human eye sight. The details of the object are accurately rendered from the biology. The precise picture so detailed challenges people's routine observation. The audience's reaction to the image was extracted. Photography restores the true meaning and removes the emotion of the individual. Cognitive illusion and emotional indifference is critical. Andy Warhol created a series of daily life items that characterize American society and culture in the process of commercializing various cities. Images such as the US dollar, rubbish, cosmetics and celebrity photos were all collage on the canvas to create entirely new paintings. Andy Warhol uses his best printmaking technique. In conjunction with video-based creative, a series of enduring works of modern art, such as Marilyn Monroe and soup cans, were created. He arranged the elements of Marilyn Monroe and soup cans in a row [8].The color is simple. The picture is tidy and monotonous. It reflects the emptiness of the Western masses in the process of city commercialization. The artistic practice of Andy Warhol makes the traditional art of advocating elegance fall heavily. The popular elements in real life can be the material of contemporary art creation in the name of art.Andy 
Warhol broke the line between elegance and vulgar from the idea of artistic creation, and popular is not art.In the way of creation, he rebelled against space relations. The principle of circular surface composition in design is used. In material selection, from everyday life, it is infinite to expand the symbolic elements of expression in artistic creation, and provide a sustainable way of creation for contemporary art.The representative work of Andy Warhol, "Marilyn Monroe" is shown in Figure 1.

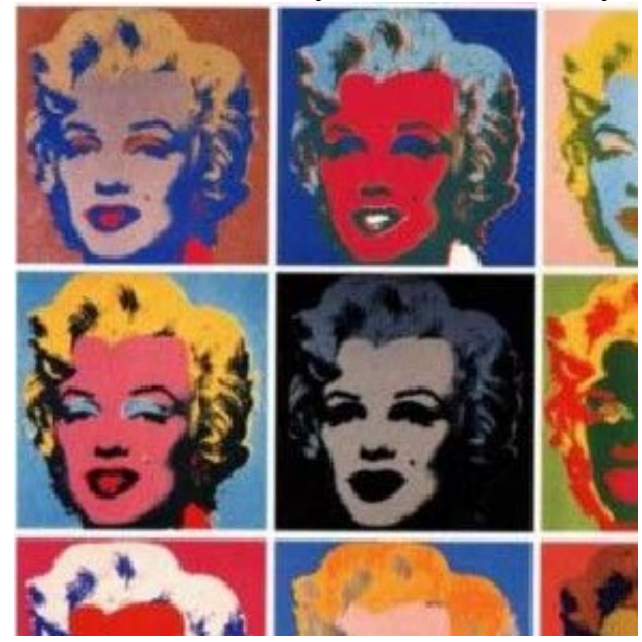

Fig 1. The representative work of Andy Warhol, "Marilyn Monroe"

Gerhard Richter is recognized as the leading figure in photographic painting. His painting and writing activities are roughly divided into three stages: Photographic realism, gray focus painting and abstract painting. He was originally a photographic realism. He has been trained by the basic skill of the figurative painting, which makes him have a deep realistic ability. However, he has been in a state of escape and has been constantly changing, which means that he is constantly developing new fields. Richter's works in different periods are very different. They start with the definition of photographic realism, which is based on photographs but keeps distance from photographs. They are not exactly the same. His figurative painting is very close to the distance from the reality. From the point of view, Richter was influenced by Andy Warhol. Richter rejected Andy Warhol's collage creation method but created a fuzzy mechanical rubbing method. Richter has a solid and rigorous painting technique. Inspired by Pauperism and Dadaism, he has innovated the fascinating linguistic form of new paintings. It guides the way that painting draws lessons from new media art images. Abstract painting of Gerhard Rich is shown in Figure 2.

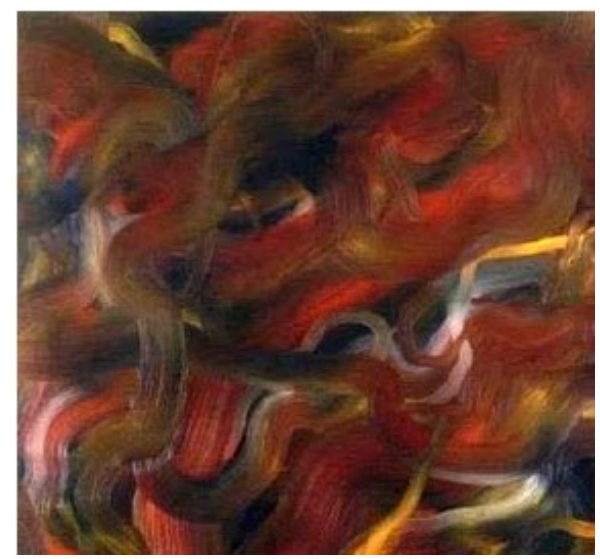

Fig 2. Abstract painting of Gerhard Rich

\section{Photographic Painting in China}

From the middle of the nineteenth Century to the middle of the twentieth Century, photography was a bewilderment to the impact of painting. The combination of painting and image puts forward various possibilities for the multiple features of the development of post-modern art. Photographic painting was produced in the middle of the twentieth Century in the West. Chinese artists, after 
receiving the information of the development of Western art, quickly absorbed the nutrients of photographic painting. After investigation, Zhang Xiao gang, a representative of modern Chinese art, expected to find some way to extend his new way from the old language. Subsequently, he created a series of Chinese typical family portrait series [9]. The concept of portrait expresses the characteristics of China. The characters in the painting are unexceptionally drawn out of their souls because of the political standards of unity. They do not know they are invisible, regardless of ages with a look of resentment. Photographic painting contributes to the practice of contemporary art in China. In the development of Chinese contemporary art, the methodology of photographic painting cannot be ignored. Hang Xiao gang's works are shown in Figure 3 and Figure 4.

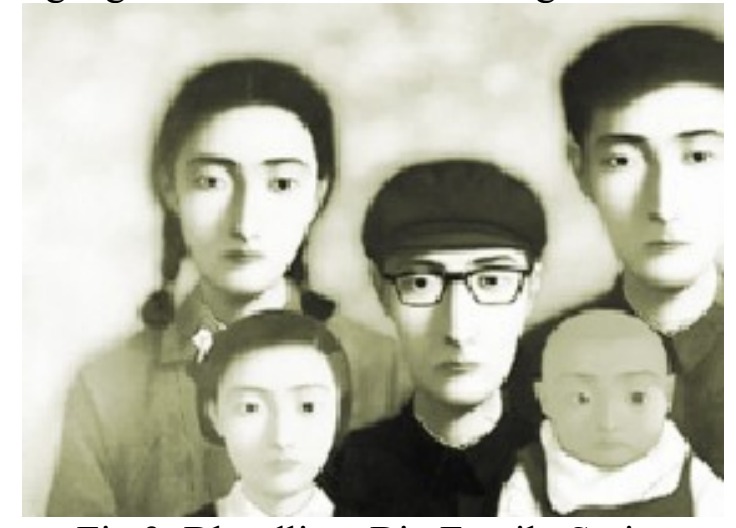

Fig 3. Bloodline: Big Family Series

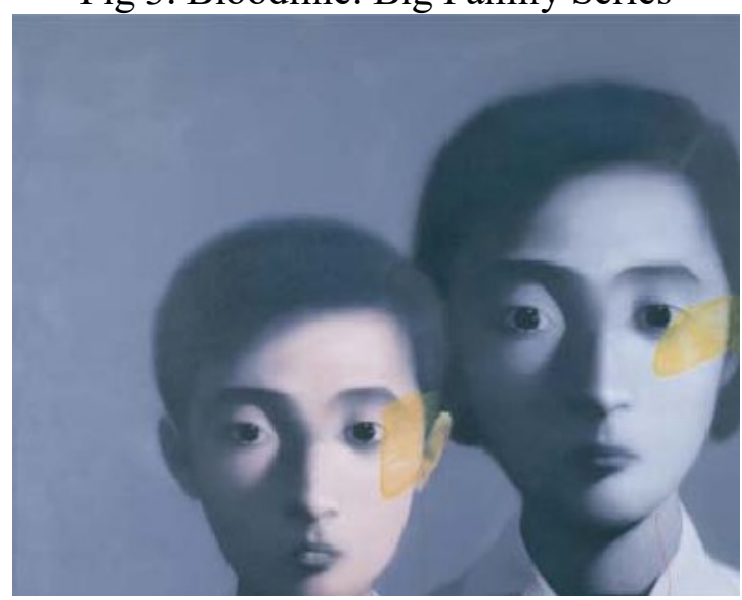

Fig 4. Bloodline Series

The contemporaneity of the art of painting is accompanied by the development of the image. The flood of images makes reading culture a flash culture. The reading of the image is even a habit. The requirement of the picture seems careless, but it depends on the truth of the literature. Photographic painting is the development of photography. The popular reading culture has developed on the basis of the translation of the language into the image. Richter's works show the open state of the natural world of physical optics. This aesthetic choice, which is directly approaching the image itself by intuition, is more difficult than the way that objects are sent to the objects by the media. It needs to seize the richest moments of things, and then make it manifest in the nervous tension. At the same time, this way also shows the respect and love of natural objects. After solving the original image of the image, the process of painting creation needs to be perfected. The visual immediacy of photography becomes art. The transformation and borrowing of painting is still the result of a methodology of painting [10]. In combination with the development of culture and society, the language of painting is more provocative for the audience's desire for direct image cognition. The painting language of the brushwork ensures the handmade features of the painting. In a variety of media boundaries, a new orientation of the value of painting is constructed. It solves the problem of the symbiosis between the development of art and the development of social science and technology. The love and bias of human understanding of image makes it more and more important for the study of physical reproduction of physical image. The world of technical image subverts the visual 
expression of the traditional painting art to the world. Expression is changed into presentation. Through a large number of images, the world is deconstructed and restored. In the sense of vision and cognition, image perception reduces the concept of using "language culture" to perceive external things. In cognition, it dispels the process of transmission to image restoration. The creation and propagation of images are applicable to art. At the same time, it is also extended to deliver other information. Image communication has gradually become an important way of mass cultural communication.

\section{The Significance of Practical Value in Photographic Painting}

The photographic painting and the painting methodology related to the photographic painting, such as photographic realism, have solved the conflict between photography and painting. From the hostile situation to the associated relationship, the boundary of painting and photography is gradually disappearing at the new level, showing the characteristics of media diversification, cultural diversity and diverse ideas. In Shoo Yang's "Chinese photographic painting", almost all "Chinese image painters" have a very professional art education background. In Shoo Yang's "Chinese photographic painting", almost all "Chinese image painters" have a very professional art education background. However, "Chinese photographic painting" completely abandoned any Chinese contemporary art education law. In fact, the technical problems of creation have been dissolved into the great environment of the culture of the times. The antibodies of the painting control the way people change in the image times. The image of the world is not a picture of the world, but the world is regarded as an image. Heidegger's theory, starting with human cognition, has been replaced by a large amount of picture information, which has replaced the old method of entering the natural cognitive society. The world of images is taking the place of the real world. People grasp the tendencies of real things by using the cognitive way of image. The visual view of the eye looks more directly from the eye to the picture, the movie TV, and Internet. The understanding of the mirror has replaced the understanding of the naked eye. The cognition of the image has changed from the virtual image to the recognition of its own.

With the development of science and technology, the mode of image production has been influenced by various achievements. The environment of survival has changed, and people have different perceptions of the image. The structure of the image produced at the technical level has alienated the old cognitive style. This alienation undoubtedly changes the formation of an objective image of human consciousness. The occurrence of consciousness is always on the premise of the existence of the world. The solution to this problem needs to be clearly explained. Photographic painting is the deep integration of its image text into life and society. With images as the media, artists break away from the fetters of traditional realism. The reconstructed image is encoded with the desire of the individual, which brings a new visual style to the development of the society and culture. The concept of Chinese photographic painting was put forward by the commentator curator Shoo Yang. Since the mid and late 90s, artists have been using the way of painting to show the visual effects of the images. Before the introduction of the concept of photographic painting in China, the visual experience of the image has seriously affected Chinese artists. In their work, the purpose is to imitate the clear and realistic effect of vision. The means is to eliminate the hand feeling of painting. The works of this kind of artists have obvious turning and borrowing of photographic images. However, in methodology, they have not completely entered the state of image expression without the expression of speech. Their works follow the outer shell of the traditional painting that describes a story. It has obviously had an artist's visual expression that is influenced by the age of the image. In the representative works of Chinese photographic painting, the authenticity of photography has become the focus of the art works. Speech expression is weakened. 


\section{Conclusion}

In the pluralistic contemporary art, Photographic painting has become a new expression of the representative art of painting. The photographic painting has been reorganized across the subject and transformed with the image resources. By using the visual effects of the image elements, the means of painting expression can be extended. Photographic painting takes advantage of the instantaneity of the fast capture object of photography, which allows some fast disappearing scenes to be fixed on the image. The scene and randomness of photography also provide the photographic painting to break the view of the traditional art. Modern science and technology provide a new means of material and technology for the creation of art. Photographic painting is a new art type and artistic style. It also has a profound influence on the artistic concept and aesthetic concept. The cultural psychological structure of the artist has been changed. It not only changes the innovation of artistic creation ideas and creative methods, but also promotes the development of art form. The photographic painting is based on the subject of the painting and is derived from the object of photography. It solves the rigid opposition between painting and photography and breaks the discourse pedigree of traditional painting.

\section{References}

[1]. Mizoram, Y., Tear, T., Hating, K., Hooky, N., Kohno, K., Araki, Y., \&Fuji Ki, M. (2014). Difference in brain activations during appreciating paintings and photographic analogs. Frontiers in human neuroscience, 8 .

[2]. Slim, A., Elgharib, M., \& Doyle, L. (2016). Painting style transfer for head portraits using convolutional neural networks. ACM Transactions on Graphics (Tog), 35(4), 129.

[3]. Kaiya, E. A. M., Campos, P. H. O. V., Risotto, M. A., Apologia, C. R., \& Lopes, F. (2014). Evaluation of the veracity of one work by the artist Di Cavalcanti through non-destructive techniques: XRF, imaging and brush stroke analysis. Radiation Physics and Chemistry, 95, 373-377.

[4]. Weasel, S. (2015). The Flash of Knowledge and the Temporality of Images: Walter Benjamin's Image-Based Epistemology and Its Preconditions in Visual Arts and Media History. Critical Inquiry, 41(2), 344-366.

[5]. Comely, D., Capogrosso, V., Arsenio, C., \&Nevins, A. (2016). Dual wavelength excitation for the time-resolved photoluminescence imaging of painted ancient Egyptian objects. Heritage Science, 4(1), 21.

[6]. Manfred, M., Barman, G., Williamson, G., Kronkright, D., Doyenne, E., Jacobs, M., \& Marengo, E. (2014). A new quantitative method for the non-invasive documentation of morphological damage in paintings using roti surface normal. Sensors, 14(7), 12271-12284.

[7]. Di Dior, C., Ardizzi, M., Massacre, D., Di Cesar, G., Gillis, G., Machete, A., \&Gales, V. (2016). Human, nature, dynamism: the effects of content and movement perception on brain activations during the aesthetic judgment of representational paintings. Frontiers in human neuroscience, 9, 705.

[8]. Coccid, C., Delaney, J. K., \&Piccolo, M. (2016). Reflectance hyper spectral imaging for investigation of works of art: old master paintings and illuminated manuscripts. Accounts of chemical research, 49(10), 2070-2079.

[9]. Bended, A., Sara, S., Akhloufi, M., Causes, J., Pradeep, C., Bat sale, J., \&Mileage, X. (2015). Subsurface imaging for panel paintings inspection: a comparative study of the ultraviolet, the visible, the infrared and the terahertz spectra. Opt-Electronics Review, 23(1), 90-101. 
[10]. Campos, P. H. O. V., Kaiya, E. A. M., Risotto, M. A., Neiva, A. C., Pinto, H. P. F., \& Almeida, P. A. D. (2014). X-ray fluorescence and imaging analyses of paintings by the Brazilian artist Oscar Pereira Da Silva. Radiation Physics and Chemistry, 95, 362-367. 